\title{
CRITICAL INFRASTRUCTURE AND ITS ECONOMY
}

\section{Jozef Klučka}

University of Žilina, Faculty of Special Engineering, Dept. of Crisis Management, ul. 1. mája 32, 01026 Žilina, Slovak Republic

\author{
(C) MESTE NGO \\ JEL category: H, H54
}

\begin{abstract}
Summary:
Globalization, increasing independence and complexity, new technologies and climate change create approach to security based on the concept of critical infrastructure. Concept of critical infrastructure is based on the basic precondition - the State should (is obliged) to fulfill vital State functions (political, economic and social) for its inhabitants. The paper deals with the role and objectives of critical infrastructure, the consequences of disasters and the possibility of their quantification. Definitions of critical infrastructure are provided (different approaches - USA, EU, Slovak republic - Act Nr. 45/2011) and expressed types of failure significant for any critical infrastructure. There are classified key drivers relevant for critical infrastructure in the Slovak republic. Within the paper is described the example explaining the concept quantification of losses. The terms like average annual loss and exceedance probability are explained. At the end of the paper the forthcoming financial mechanism is mentioned. This mechanism is also connected to financing of the critical infrastructure of European Union (EU) member states. In the paper are expressed objectives concerning EU Internal Security Strategy. Under consideration is the Fund for interior security in EU for years 2014-2020 to support the Strategy. The financial conditions of the Fund are briefly described in the paper.
\end{abstract}

\section{Keywords:}

Critical infrastructure, catastrophe, economic impact, quantification of losses

\section{Introduction}

One of the government's functions is to protect and secure its citizens. Globalization, increasing independence and complexity, new technologies

The address of the author:

Jozef Klučka

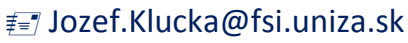

and climate change create new challenges for the government and its approach to security policy. The approach identifies significant assets in terms of State functions and protection of citizens' life in it. This approach underlines the concept of critical infrastructure $(\mathrm{Cl})$. It is based on identification of elements that are the most important for the fulfillment of vital State functions. 
Each country is highly dependent on specific operations of $\mathrm{Cl}$ that fulfill supply of basic goods and services. They are e.g electric energy supply, IT services, waste disposal. Disruptions may have huge impact on the population (business and non-business sectors). Therefore the fundamental objective is to maintain the operability of the $\mathrm{Cl}$ (within a country as well as EU - speaking about the member state). The specific aspect of $\mathrm{Cl}$ is that any disruption of a $\mathrm{Cl}$ element can affect huge economic losses (e.g large scale power blackout, floods and other catastrophes).

The concept of the $\mathrm{Cl}$ has its political, social and economic dimensions.

\section{Catastrophe and its economic impact}

Generally, there can be identified different possible trajectories of the disaster consequences (compare (Hochrainer, 2006))

There are different trajectories of possible disaster consequences (e.g. GDP, profit). The possible trajectories are:

- discontinuity of a system; the consequences of a disaster are so substantial that it results into system failure,

- negative long term effect; the trajectory of the long term consequences is under the projected line without additive disaster event,

- positive long term effect; the trajectory of the long term disaster consequences is above the projected line without additive disaster event.

The consequence of a disaster can have positive, negative or neutral impact on the output - in case of a state the representative outcome is GDP (GDP/inhabitant). In practice the isolated disaster (localized in a subregion) can cause fundamental consequences or on the other side (with other aspects of environment) it can start rapid economic growth of the subregion, region or the country.

There are cross-sectional criteria that help to identify elements of critical infrastructure published in the paper. These cross-sectional criteria are based on the law (Nr. 45/2011 About Critical Infrsastructure, 2011, p. 436): a) the number of vulnerable people, including those killed and injured persons,

b) the economic impact, which includes:
a. economic losses
b. deterioration of goods
c. deterioration in the quality of public services

d. negative impact on the environment

c) impact on the population degrading the quality of citizens' life in terms of
a. severity of loss of supply and the recovery time
b. severity of failure in providing public services and recovery time
c. availability of replacement supplies
d. availability of compensation for the services provided in the public interest.

The economic impact of the failure of critical infrastructure can be quantified via direct or indirect economic losses. The other approach to the failure of critical infrastructure will be explained in the paragraph - Quantification of losses.

\section{Critical infrastructure}

Critical infrastructure $(\mathrm{Cl})$ is defined as following: "Include those physical resources, services, information technology facilities, networks and infrastructure assets, which, if disrupted or destroyed would have a serious impact on the health, safety, security, economic or social wellbeing of either." (EU, 2011), (114/EC, 2008).

The Critical Infrastructure Assurance Office (CIAO): "the framework of interdependent networks and systems comprising identifiable industries, institutions (including people and procedures), and distribution capabilities that provide a reliable flow of products and services essential to the defense and economic security of the USA, the smooth functioning of governments at all levels, and society as a whole. " (Rinaldi \& all., 2001)

The Act Nr. 45/2011 on critical infrastructure was approved in the Slovak Republic. It provides a definition of critical infrastructure elements as follows: "Disruption or destruction of civil engineering building, service in the interest of public and information system in the sector, having potentially serious adverse consequences or the conduct of economic and 
social functions of the Country, and thereby the impact on the quality of life, protection of life, health, safety, property and environment according the sector criteria and cross-cutting criteria." (Nr. 45/2011 About Critical Infrsastructure, 2011)

Critical infrastructure can be characterized:

- it consists of assets, products, services,

- consequences of its dysfunctions have extreme impact on the whole society (economic and socio-political environment),

- it is a network of assets, products or services, whose activities, performance act in the network of interrelations.

Critical infrastructure relates to interdependency. It is a bidirectional relationship between two infrastructures through which the state of each infrastructure influences or is correlated to the state of the other. Interdependency can be seen as the two-level system:

- First level - a system of relations within the identified infrastructure (e.g. transport)

- Second level - a system of relations to others, different sectors (e.g. relations between transport and telecom, banking and finance ) and sub second level defined as coupling order - indicates whether two infrastructures are directly connected to each other or indirectly coupled through one or more intervening infrastructures compare to (Rinaldi \& all., 2001).

There are three types of failure within a critical infrastructure (Rinaldi \& all., 2001):

- cascading - when a disruption in one infrastructure causes the failure of a component in a second one,

- escalating - when an existing disruption in one infrastructure exacerbates an independent disruption of a second one,

- common cause - when two or more infrastructures networks are disrupted at the same time.

The key drivers and trends of critical infrastructure in the Slovak republic are:

- the infrastructure is owned and managed by public and private sectors and the average age of structures increases,

- the cooperation between private sectors and state organizations is the challenge for the future; only cooperation can fulfill objectives and increase security,

- the improvement, investments and maintenance costs are rising,

- the government is financing critical infrastructures - it is seen as the state objectives but the financial sources tend be more and more limited,

- the cyber sphere started to be the most critical part of the infrastructure

- functionality of critical infrastructure is also determined by climate change and technological innovations.

\section{$4 \quad$ Quantification of losses}

Occurrence of an event - a catastrophe can be quantified by the yearly occurrence probability $p_{i}$ and related loss $\mathrm{L}_{\mathrm{i}}$. For events from tab. 1 is assumed that they are independent Bernoulli distribution that can be described (Grossi \& Kunrenther, 2005):

$P\left(E_{i}\right.$ occurrence $)=p_{i}$

If the event $E_{i}$ does not occur, then the loss $L_{i}=0$. The amount of the expected loss $\mathrm{EL}_{i}$ of an event $E_{i}$ is

$E L_{i}=p_{i}^{*} L_{i}$

The total loss for all events during a year is defined as AAL - average annual loss and can be quantified

$\mathrm{AAL}=\sum_{i} E L_{i}=\sum_{i} p_{i} * L_{i}$

Exceedence probability for a given loss can be computed as:

$\operatorname{EP}\left(L_{\mathrm{i}}\right)=$

$P\left(L>L_{i}\right)=1-P\left(L \leq L_{i}\right)=1-\prod_{j=1}^{i}\left(1-p_{i}\right)$

The final value EP (Li) gives the yearly probability that the loss will overcome the defined value. EP curve can identify probable maximum loss PML. PML is a subjective measure of risk.

An insurer can apply EP curve (fig.1) to define amount of loss that can be on the predefined probability level. PML can be adversary defined 
Klučka J. Critical infrastructure and its economy

MEST Journal Vol.1 No.1 pp. 65 - 71

as the yearly probability to overcome prespecified loss. In the case that frequency of a catastrophe is once per 10 years than it is a $10 \%$ annual probability of exceedence. In the example the frequency of an event is once per
10 years. For PML it is low frontier of loss that shows $10 \%$ probability to overcome EP curve. From the Picture 2 is clear that PML is about 2,6 mil.€.

Tab.1 Average annual loss -example (based on (Grossi \& Kunrenther, 2005))

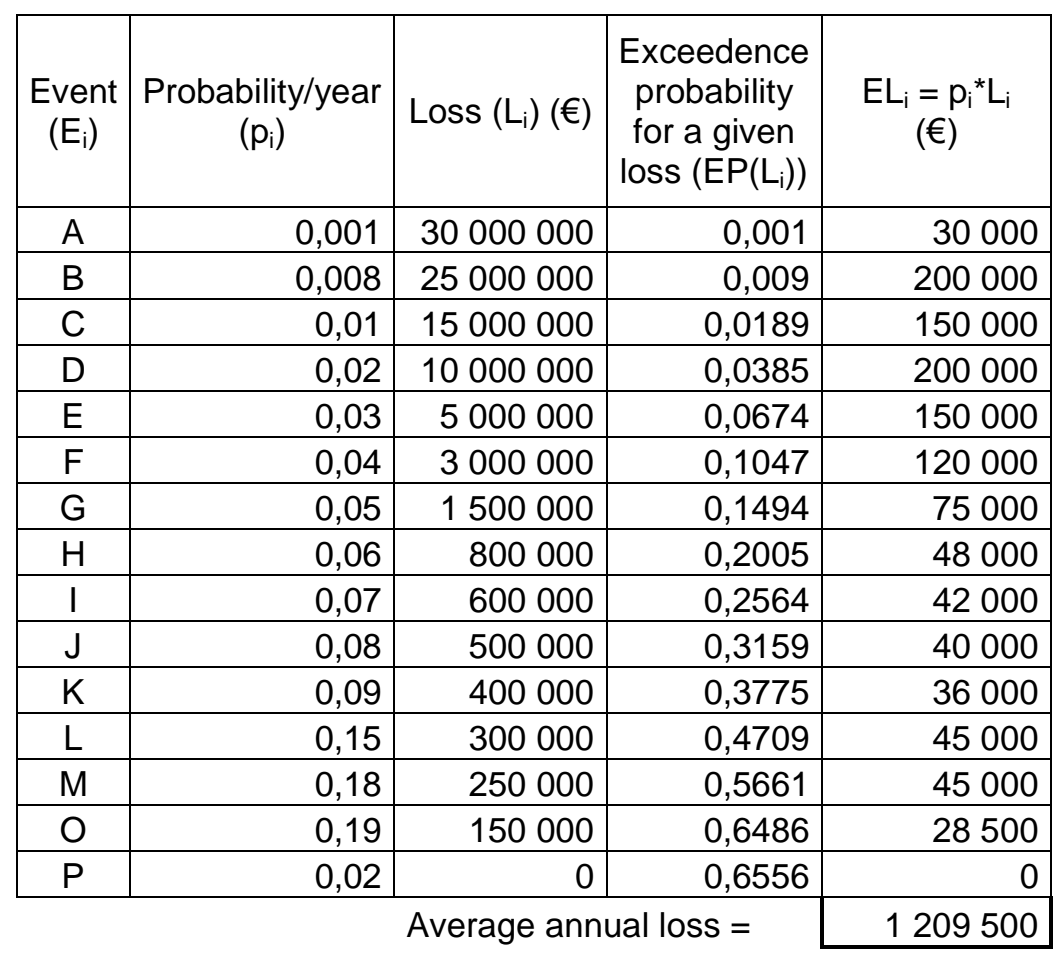

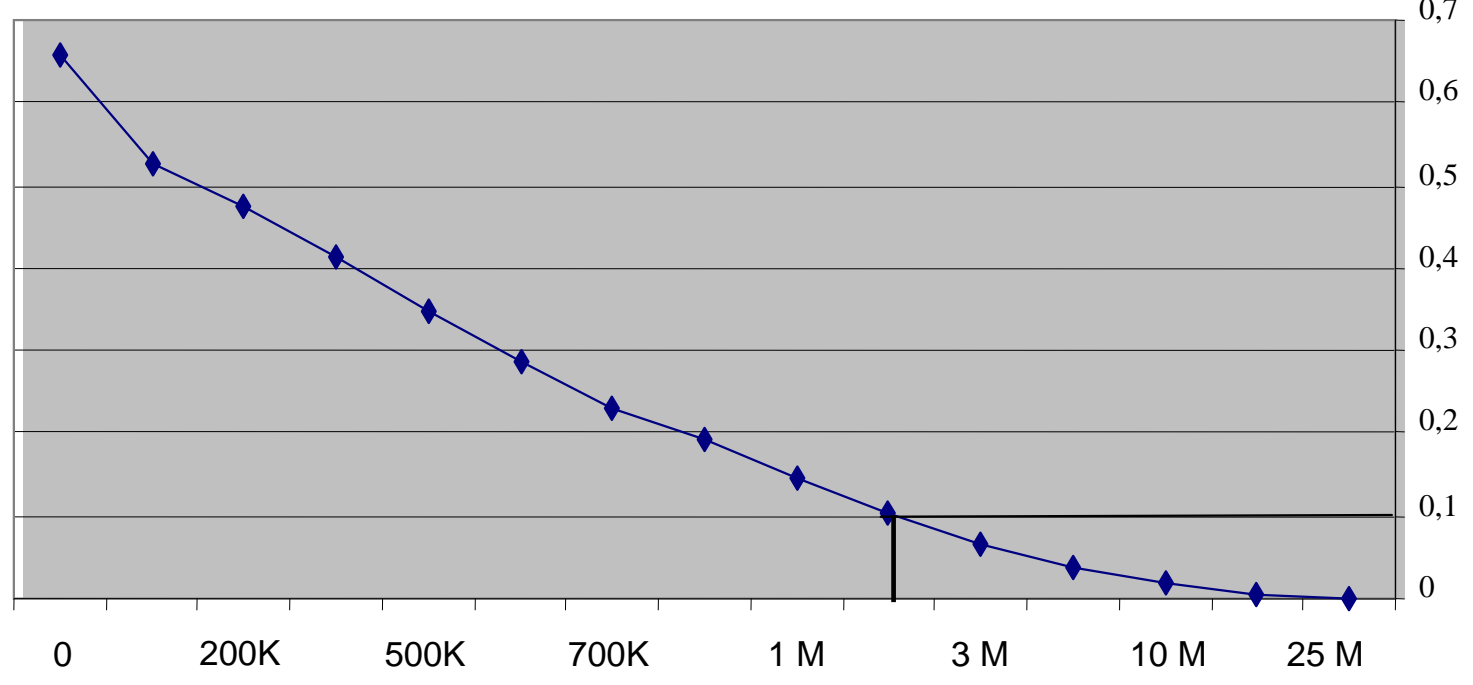

$0,7 \operatorname{EP}\left(L_{i}\right)$

Loss

Fig. 1 Relation between loss and risk probability 
Let us assume that we quantify for different EP (Li) expected losses ELi .

Tab.2 Example based on (Grossi \& Kunrenther, 2005)

\begin{tabular}{|c|c|c|c|c|c|}
\hline $\begin{array}{l}\text { Return } \\
\text { time } \\
\text { (years) }\end{array}$ & $\operatorname{EP}\left(\mathrm{L}_{\mathrm{i}}\right)$ & $\begin{array}{c}E L_{i} \\
\text { Model } \\
\text { A } \\
\text { (mil.€) }\end{array}$ & $\begin{array}{c}E L_{i} \\
\text { Model } \\
\text { B } \\
\text { (mil. } € \text { ) }\end{array}$ & $\begin{array}{c}E L_{i} \\
\text { Model } \\
\text { C } \\
\text { (mil.€) }\end{array}$ & $\begin{array}{l}\text { Linear } \\
\text { Combination } \\
\text { (mil.€) }\end{array}$ \\
\hline 10000 & $0.01 \%$ & 40.00 & 45.00 & 70.00 & 50.00 \\
\hline 5000 & $0.02 \%$ & 38.00 & 43.20 & 69.20 & 48.40 \\
\hline 2000 & $0.05 \%$ & 36.00 & 42.10 & 67.20 & 46.85 \\
\hline 1000 & $0.10 \%$ & 35.50 & 40.10 & 65.10 & 45.20 \\
\hline 500 & $0.20 \%$ & 34.00 & 38.70 & 63.20 & 43.65 \\
\hline 200 & $0.50 \%$ & 30.00 & 36.00 & 60.90 & 40.73 \\
\hline 100 & $1.00 \%$ & 27.60 & 34.50 & 58.20 & 38.70 \\
\hline 50 & $2.00 \%$ & 27.40 & 32.10 & 56.90 & 37.13 \\
\hline 20 & $5.00 \%$ & 25.00 & 30.80 & 54.20 & 35.20 \\
\hline 10 & $10.00 \%$ & 20.00 & 28.60 & 53.90 & 32.78 \\
\hline 5 & $20.00 \%$ & 15.80 & 25.90 & 52.10 & 29.93 \\
\hline 2 & $50.00 \%$ & 14.20 & 23.10 & 51.10 & 27.88 \\
\hline weight & & $25 \%$ & $50 \%$ & $25 \%$ & \\
\hline
\end{tabular}

In the case we identify EP of an event $0.5 \%$ it means that the return time in years is 200 years, otherwise the event will occur with frequency once per 200 years. Other very useful interpretation of the model is - that functionality of a critical infrastructure (any assets) can be identified by the resistance. Following approach is applied in the UK: „as a minimum essential services provided by Critical National Infrastructure (CNI) in the UK should not be disrupted by a flood event with an annual likelihood of 1 in 200 (0.5\%)". (Keeping the Country Running Natural Hazards and Infratsructure, 2011) The Government set out explicit standards against which investments could be planned and appraised and suggested that a 1 in $200(0.5 \%)$ annual probability event was a reasonable starting point to protect Critical National Infrastructure from flooding.

For the data in the example at 1-in-10 year event or $10 \%$ probability of exceedance, the loss estimates in the interval 20,00 to 53,90 mil. $€$. By applying linear combination the loss to this frequency is 32.78 mil€

In the example model A, B, C can represent individual sectors and expected losses. Application of different weights we can get data that allow analyzing the current problem in more sophisticated background.

\section{$5 \quad$ Critical infrastructure financing}

After identification of elements of $\mathrm{Cl}$ financing decision taking is needed. The traditional sources are state budget and state transfer to private owners - subsidy to cover additional costs to keep predefined level of security. Based on the Slovak law:

"The operator is entitled to a financial contribution to meet the obligations associated with the implementation of security measures to protect elements of $\mathrm{Cl}$ and it is entitled towards central authority in the field of critical infrastructure, to the sector the operator is associated and when the central authority will appoint the organization and this obligation is based on the other generally binding legal regulation. The regulation to provide financial subsidies should be submitted by the competent central authority" (Nr. 45/2011 About Critical Infrsastructure, 2011).

The Security belongs to the one of the EU objectives. EU Internal Security Strategy (in 2010) focuses on the following strategic objectives:

- prevention of cross-border, serious and organized crime and fight against it,

- prevent terrorism, radicalization and recruitment, 
Klučka J. Critical infrastructure and its economy

MEST Journal Vol.1 No.1 pp. 65 - 71

- increase the capacity for critical infrastructure protection across all economic sectors,

- increase the resistance of Europe to crisis and disasters. (EU, 2011)

With the objective to improve safety there is a proposal (working document) to establish Fund for interior security in EU for years 2014-2020. Financial sources allocated for the Fund will be 1128 mil.€ for this period. The sum will be split in ratio $50 / 50$ for member states and EU authority - it means 564 mil. $€$ will be delivered to member states to support national programs and measures of EU. EU will apply the rest (50\%) for the measures within direct or indirect subsidies.

\section{CONCLUSION}

The concept of organizational resilience can be defined as the ability of an organization to anticipate, plan and respond to the hazards and threats. The infrastructure resilience consists of four elements (Keeping the Country Running Natural Hazards and Infratsructure, 2011):

- resistance,

- reliability,

- redundancy,

- response and recovery.

There is strategically important to build critical infrastructure that is based on the four pillars. The finance and the ability to quantify losses are preconditions. The losses should be identified and also should be identified the relations, dependencies among different items of $\mathrm{Cl}$. The objective is to define mechanism that optimizes investments and pre-defined level of $\mathrm{Cl}$ security. In the long term seems to be crucial to identify financial schemes based on non-state funding.

\section{Works Cited}

114/EC, E. (2008). On the Identification and Designation of European Critical Infrastructures and Assesssment of the Need to Improve their Protection. Brussels.

EU, C. o. (2011). Interinstitutional document (working document). Bruussels: EU.

Grossi, P., \& Kunrenther, U. e. (2005). Catastrophe Modelling. Berlin: Springer.

Hochrainer, S. (2006). Macroeconomic Risk Managemenent against Natural Disasters. Wien: DUV.

Keeping the Country Running Natural Hazards and Infratsructure. (2011). Retrieved 12 12, 2012, from www.cabinetoffice.gov.uk

Nr. 45/2011 About Critical Infrsastructure. (2011). List of Bills, 436-450.

Rinaldi, S., \& all., a. (2001). Identifying, Understanding and Analyzing *Critical Infrastructure

Dependencies. Retrieved 12 10, 2012, from www.ce.cmu.edu

The paper was published within the project APVV-0471-10 Security of Critical Infrastructure in Transport.

Received for publication: $\quad 25.09 .2012$

Revision received: $\quad$ 14.12.2012

Accepted for publication: $\quad 21.12 .2012$ 
Klučka J. Critical infrastructure and its economy MEST Journal Vol.1 No.1 pp. $65-71$

\section{How to cite this article?}

Style - APA Sixth Edition:

Klučka, J. (2013, 01 15). Critical infrastructure and its economy. (Z. Čekerevac, Ed.) MEST Journal, 1(1), 65-71. Retrieved from www.meste.org/mest/MEST 1 2013/ 07.pdf.

doi: 10.12709/mest.01.01.01.07.pdf

Style - Chicago Fifteenth Edition:

Klučka, Jozef. "Critical infrastructure and its economy." Edited by Zoran Čekerevac. MEST Journal (MESTE NGO) 1, no. 1 (01 2013): 65-71.

Style - GOST Name Sort:

Klučka Jozef Critical infrastructure and its economy [Journal] = Critical infrastructure and its economy // MEST Journal / ed. Čekerevac Zoran. - Belgrade - Toronto : MESTE NGO, 01 15, 2013. 1 : Vol. 1. - pp. 65-71.

Style - Harvard Anglia:

Klučka, J., 2013. Critical infrastructure and its economy. MEST Journal, 15 01, 1(1), pp. 65-71.

Style - ISO 690 Numerical Reference:

Critical infrastructure and its economy. Klučka, Jozef. [ed.] Zoran Čekerevac. 1, Belgrade - Toronto : MESTE NGO, 01 15, 2013, MEST Journal, Vol. 1, pp. 65-71. 